\title{
Applying New Technologies to Transform Blueberry Harvesting
}

\author{
Fumiomi Takeda ${ }^{1, *}$, Wei Q. Yang ${ }^{2}$, Changying $\mathrm{Li}^{3}{ }^{3}$, Andris Freivalds ${ }^{4}$, Kiseok Sung ${ }^{4}$, Rui $\mathrm{Xu}^{3}$, \\ Bo $\mathrm{Hu}^{5}$, Jeffrey Williamson ${ }^{6}$ and Steven Sargent ${ }^{6}$ \\ 1 United States Department of Agriculture-Agricultural Research Service, Appalachian Fruit Research \\ Station, Kearneysville, WV 25430, USA \\ 2 North Willamette Research and Extension Center, Oregon State University, Aurora, OR 97002, USA; \\ wei.yang@oregonstate.edu \\ 3 College of Engineering, University of Georgia, Athens, GA 30602, USA; cyli@uga.edu (C.L.); \\ asilan@uga.edu (R.X.) \\ 4 Harold and Inge Marcus Department of Industrial and Manufacturing Engineering, \\ The Pennsylvania State University, State College, PA 16802, USA; axf@engr.psu.edu (A.F.); \\ kys5239@psu.edu (K.S.) \\ 5 Qingdao Blueberry Engineering Center, Jiaonan City, Qingdao 266400, China; hugocooper@hotmail.com \\ 6 Horticultural Sciences Department, University of Florida, Gainesville, FL 32611, USA; jgrw@ufl.edu (J.W.); \\ sasa@ufl.edu (S.S.) \\ * Correspondence: fumi.takeda@ars.usda.gov; Tel.: +1-304-725-3451
}

Academic Editors: Esther van der Knaap, Cecilia E. McGregor and Francesco Montemurro Received: 7 March 2017; Accepted: 27 April 2017; Published: 4 May 2017

\begin{abstract}
The growth of the blueberry industry in the past three decades has been remarkably robust. However, a labor shortage for hand harvesting, increasingly higher labor costs, and low harvest efficiencies are becoming bottlenecks for sustainable development of the fresh market blueberry production. In this study, we evaluated semi-mechanical harvesting systems consisting of a harvest-aid platform with soft fruit catching surfaces that collected the fruit detached by portable, hand-held, pneumatic shakers. The softer fruit catching surfaces were not glued to the hard sub-surfaces of the harvest-aid platform, but suspended over them. Also, the ergonomic aspect of operating powered harvesting equipment was determined. The pneumatic shakers removed 3.5 to 15 times more fruit $(\mathrm{g} / \mathrm{min})$ than by hand. Soft fruit catching surfaces reduced impact force and bruise damage. Fruit firmness was higher in fruit harvested by hand compared to that by pneumatic shakers in some cultivars. The bruise area was less than $8 \%$ in fruit harvested by hand and with semi-mechanical harvesting system. The percentage of blue, packable fruit harvested by pneumatic shakers comprised as much as $90 \%$ of the total, but less than that of hand-harvested fruit. The ergonomic analysis by electromyography showed that muscle strain in the back, shoulders, and forearms was low in workers operating the light-weight, pneumatic shakers that were tethered to the platform with a tool balancer. The new harvesting method can reduce the labor requirement to about 100 hour/hectare/year and help to mitigate the rising labor cost and shortage of workers for harvesting fresh-market quality blueberries.
\end{abstract}

Keywords: fruit detachment; harvest efficiency; blueberry; shaking equipment; mechanical harvesting; ergonomics; instrumented sphere; acceleration; impact damage; impact recording device

\section{Introduction}

The highbush blueberry (Vaccinium corymbosum hybrids) industry in the United States (U.S.), South America, China, and elsewhere has experienced a phenomenal growth in the past three decades [1]. Per capita consumption of blueberries during this period doubled as consumers have become more 
aware of health benefits of blueberries. In 2011, blueberry production in the U.S. was 231 MT, about $57 \%$ of world production. In the U.S. about $60 \%$ of production is packed for the fresh market, of which the majority is still hand harvested [2]. Outside the U.S., much of the blueberry is hand harvested and for fresh market distribution to North American, Asian, and European markets. By 2014, blueberry production across five continents had risen to 450 MT. By 2017, the global blueberry production is projected to approach $680 \mathrm{MT}$, with about half coming from North America [3].

As the blueberry production acreage continues to increase, growers foresee a shortage of labor for hand harvesting, increasingly high labor cost, and low harvest efficiencies becoming bottlenecks for sustainable development of the fresh market blueberry production. Hand harvesting blueberries is labor-intensive and requires up to $1200 \mathrm{~h}$ of labor per hectare annually [4]. In contrast, commercially available over-the-row (OTR) mechanical harvesters (Figure 1) can cut harvest labor to $25 \mathrm{~h} /$ hectare for blueberries destined for processing and reduce the cost of harvest from $\$ 2.80 / \mathrm{kg}$ by hand to $\$ 0.26 / \mathrm{kg}[4,5]$. Although OTR harvesters can significantly cut harvest labor, they now cost as much as $\$ 240,000$ per unit making them unaffordable for small- and medium-size blueberry farms.

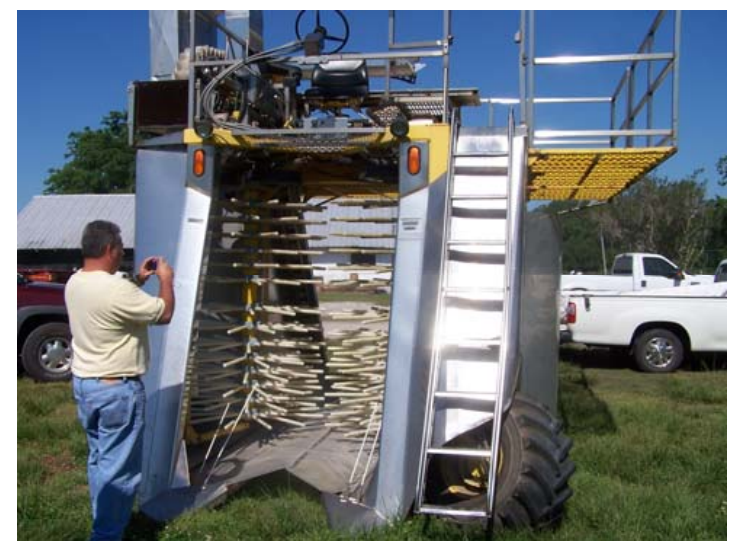

Figure 1. A commercial over-the-row (OTR) berry harvester manufactured by Littau Harvester (Stayton, OR, USA). OTR berry harvesters are self-propelled with the driver positioned on the top platform. The frame is sufficiently sized to straddle blueberry plants that could be $>2.5-\mathrm{m}$ tall and $>1.5-\mathrm{m}$ wide. Inside the tunnel of the harvester frame, two vertically-oriented rotary, drum shakers are mounted. Closer to the ground, there are catcher plates and conveyor belts installed to collect and transfer detached fruit to the rear and some units to the top platform. Fruit then passes through a blower to separate the trash and debris (e.g., leaves, small berries, and stems) before dropping into a lug.

Research has shown that blueberries harvested by OTR machines have significantly reduced shelf life [4,6-8], and as much as $25 \%$ of fruit is lost to the ground, thus reducing the packable yield [8]. Also, blueberries harvested with conventional OTR harvesters exhibit excessive bruise damage and have lower fruit firmness $(\mathrm{g} / \mathrm{mm})$ than hand-harvested blueberries, and their quality deteriorates during $>3$ week postharvest cold storage required for marketing and for late-season distribution $[4,7,9]$. This is especially the case in production areas such as the Southeast U.S. (e.g., Florida and Georgia) where hot temperatures prevail during the harvest period, and certainly mechanical harvesters cannot be used to harvest blueberries in South America for marine transport for distant markets in Asia and North America which may take as long as 4 to 5 weeks before reaching the consumers.

Much of quality loss in fruit harvested by OTR machines comes from the direct contact between the machine-detached fruit and harvester's hard surfaces such as the plastic beater rods, plastic or fiberglass catcher plates when the detached fruit drop from the bush onto the catch pans and to the conveyor belt, and when the fruit drop from the conveyor belt into the fruit lugs. Yu et al. [10,11] and $\mathrm{Xu}$ et al. [12] measured the mechanical impacts using a miniaturized blueberry impact recording device (BIRD). These studies showed that the impacts created by rotary harvester generated not only smaller number but also lower magnitude than the impacts created by the sway and slapper harvesters. 
However, in all three harvesters, the real-time impact analysis revealed that the maximum impact value was recorded when the detached fruit and sensor contacted the catch plates. Also, a close-up video recording of the harvest operation showed that blueberry fruit was more likely to collide with the catch plates than with the tunnel wall $[10,11]$.

Over the years, mechanical harvesters have been developed in attempts to harvest blueberries for the fresh market, but with a limited success $[4,9,13]$. Also, there has been research to determine the effect of modifying fruit catching surfaces on blueberry quality. The team led by Peterson $[13,14]$ designed a blueberry harvester called the V45 blueberry harvester, which had two shaker drums that were angled $45^{\circ}$ from horizontal and a prow at the front of the harvester. With this design, the fruit-laden canes were pushed away from plant's crown and the shaking tines engaged the plants from the top. An intermediate fruit catching surface located about $30 \mathrm{~cm}$ above the catcher plates on each side decreased the initial falling height for detached blueberries. The padding on the intermediate fruit catching surface reduced the mechanical impact force to the fruit landing on it. Also, ground loss was reduced because the bending of canes outward positioned much of fruit away from the crown [13]. With conventional OTR machines (Figure 1), in contrast, the canes are fed between two vertically oriented drums and fruit-laden canes are held upright and whorls of tines engage canes from the side. Detached fruit falls as much as $1.5 \mathrm{~m}$ through the vibrating tines and lands on catcher plates located at the bottom of the harvester. Brown et al. [4] and Xu et al. [12], have shown blueberry fruit that fall more than $60 \mathrm{~cm}$ onto plastic catch plates sustain extensive bruise damage. However, to date, harvesters that minimize drop height have not been commercially available. Only about six V45 blueberry harvesters were ever built because it was not widely accepted by growers due to (a) limited operating speed; (b) non-durable fruit catching surface on the V45 harvester; and (c) special cane training and pruning required to minimize plant damage [9].

Attempts have been made to harvest blueberries with semi-mechanical harvesting systems [15-18]. In these studies, hand-held, vibrating shakers (e.g., Model H1, BEI Inc., South Haven, MI, USA) and Hook Shaker (Campagnola SRL, Zola Predosa-Bologna, Italy) were used to detach blueberries from the plant and two portable fruit catching frames placed around two plants were used to collect the fruit (Figure 2). The frame is manually positioned against the plant and required additional handling to pour harvested fruit into lugs. The use of a netted fabric on the portable catch frame did result in mechanically detached fruit with little or no bruise damage [16]. However, the BEI's H1 vibrator weighs $2.4 \mathrm{~kg}$ and has a pistol grip attached to the shaker head. Holding the shaker by one hand made it difficult for a worker to use it continuously for a long period [15]. The hook shaker used in Chile [17] engaged one cane at a time limited harvest efficiency not much greater than the level achieved by hand harvesting. In a recent nation-wide grower survey conducted as part of the U.S. Department of Agriculture, National Institute of Agriculture and Food, Specialty Crop Research Initiative Project No. 2014-07897, over 300 blueberry growers responded that they would welcome a semi-mechanical harvesting system that would improve harvest efficiency, capacity, and fruit quality, and at the same time minimize ground loss and be less expensive than currently available commercial OTR blueberry harvesters.

It is critical to optimize the operating parameters for mechanization and hand-held shakers (e.g., vibration frequency, magnitude, angle at which the shaker is engaged with the blueberry bush) for increasing harvest efficiency and capacity, and to reduce labor cost. Shaker optimization can be achieved by better understanding how the vibrational force from the shaker is transmitted to the bush and its branches and fruit as well as to the operator. Such analysis will document the potentially excessive frequencies and high forces transmitted from harvesting equipment to the operator and whether the effect of worker's limb postures could result in work-related musculoskeletal disorders (WRMSDs) [19]. In agricultural work, WRMSDs can account for as much as $28 \%$ of the 200,000 lost-time injuries on U.S. farms, whereby hand/wrist problems were a significant proportion of these injuries [20]. In addition to improving harvest efficiency compared to hand harvesting, semi-mechanical harvesting systems should reduce worker fatigue and stress level when the weight 
of the shaking apparatus is counter-balanced with a tool balancer and modifications are made to the shaker handle to reduce the transmission of vibration to operator's hand.

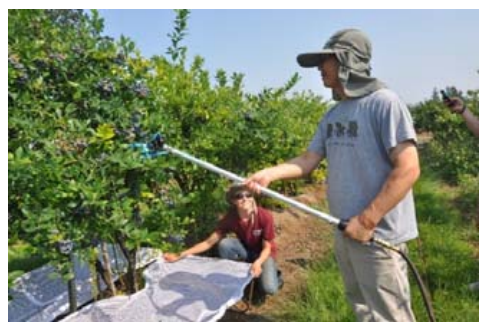

(a)

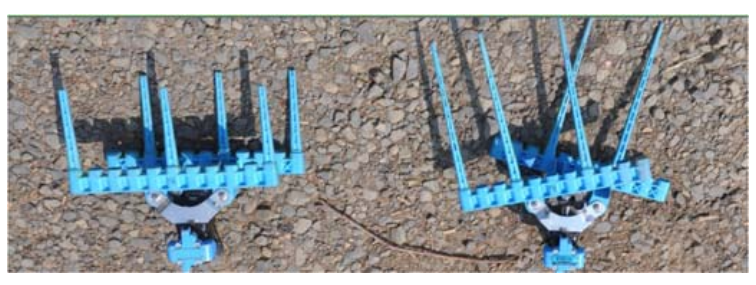

(b)

Figure 2. (a) A hand-held, pneumatic shaker (Golia model) engaging a blueberry plant with mature fruit. Two portable catch frames each with netted fabric were placed tightly against the plants for collecting detached blueberries; (b) The shaking heads of Golia olive shaker (Campagnola, Bologna, Italy) used in the study shown with short (12.5-cm long (left)) and long (23-cm long (right)) tines.

The objectives of this study were to (i) compare the quality and quantity of blueberries harvested by hand and with a pneumatically-powered olive shaker; (ii) develop better understanding of the interaction between machine parts and the fruit; (iii) develop a modified fruit-catching surface; and (iv) perform time-motion analysis and physiological status of workers operating hand-held blueberry harvesting equipment.

\section{Results}

\subsection{Shaker Performance and Fruit Quality}

The pneumatic shakers removed as much as 6 times more fruit $(\mathrm{g} / \mathrm{min})$ than by hand in 'Draper' and 'Legacy' and nearly 16 times in 'Liberty' blueberries (Table 1). All samples lost weight (1\% to $5 \%$ ) during 4 weeks in cold storage, but the difference between harvest parameters for pneumatic shakers was small. Brix was slightly lower $\left(<0.5^{\circ}\right.$ Brix $)$ and TA was higher $(<0.4 \%)$ in fruit harvested with pneumatic shakers than by hand or OTR harvester. The operating pressure and tine length has little effect on fruit quality parameters, but more fruit $(3 \times$ to $5 \times)$ was harvested with long tines on the shaker operated at $454 \mathrm{KPa}$ compared to a shaker with short tines and operated at $310 \mathrm{KPa}$. Fruit removal efficiency was quite good at all shaker settings. More than $90 \%$ of fruit of 'Draper', 'Legacy' and 'Liberty' NHB blueberry detached by the Golia shaker were sorted as blue and acceptable for packaging.

Table 1. The effect of shaker parameters on fruit detachment of 'Draper', 'Legacy', and 'Liberty' northern highbush blueberry. ${ }^{x}$

\begin{tabular}{|c|c|c|c|c|c|c|c|}
\hline \multirow{2}{*}{\multicolumn{2}{|c|}{ Shaker Setting }} & \multicolumn{6}{|c|}{ Cultivar } \\
\hline & & \multicolumn{2}{|c|}{ Draper } & \multicolumn{2}{|c|}{ Legacy } & \multicolumn{2}{|c|}{ Liberty } \\
\hline $\begin{array}{l}\text { Pressure } \\
\text { (psi) }\end{array}$ & $\begin{array}{l}\text { Tine Length } \\
\text { (cm) }\end{array}$ & $\begin{array}{l}\text { Harvest Rate } \\
\text { (kg/min) }\end{array}$ & $\begin{array}{c}\text { Blue Fruit } \\
(\%)\end{array}$ & $\begin{array}{l}\text { Harvest Rate } \\
\text { (kg/min) }\end{array}$ & $\begin{array}{c}\text { Blue Fruit } \\
(\%)\end{array}$ & $\begin{array}{l}\text { Harvest Rate } \\
\text { (kg/min) }\end{array}$ & $\begin{array}{c}\text { Blue Fruit } \\
\text { (\%) }\end{array}$ \\
\hline 45 & 12.5 & $0.80 \mathrm{~b}^{\mathrm{y}}$ & $81 \mathrm{~b}$ & $2.47 \mathrm{a}$ & $94 \mathrm{~b}$ & $1.09 \mathrm{ab}$ & $96 \mathrm{a}$ \\
\hline 45 & 22.5 & $1.50 \mathrm{a}$ & $78 \mathrm{~b}$ & $2.97 \mathrm{a}$ & $93 \mathrm{~b}$ & $1.93 \mathrm{a}$ & $91 \mathrm{a}$ \\
\hline 65 & 12.5 & $0.97 \mathrm{~b}$ & $83 \mathrm{~b}$ & $0.95 \mathrm{~b}$ & $91 \mathrm{~b}$ & $1.47 \mathrm{a}$ & $97 \mathrm{a}$ \\
\hline 65 & 22.5 & $1.54 \mathrm{a}$ & $82 \mathrm{~b}$ & $2.55 \mathrm{a}$ & $85 c$ & $2.03 \mathrm{a}$ & $91 \mathrm{a}$ \\
\hline \multicolumn{2}{|c|}{ Hand harvest } & $0.25 \mathrm{c}$ & $89 a$ & $0.48 \mathrm{c}$ & $98 \mathrm{a}$ & $0.13 \mathrm{~b}$ & $92 \mathrm{a}$ \\
\hline
\end{tabular}

${ }^{x}$ Blueberry plants were either shaken with hand-held shaker for 1 min or hand harvested for 5 min to calculate harvest rate $(\mathrm{kg} / \mathrm{min})$. Harvested fruit was sorted into blue (ripe) and red/green (immature) groups to calculate the percent of blue fruit detached by different harvesting methods. ${ }^{\mathrm{y}}$ Means within a column followed by the same letter are not significantly different at $p=0.05$. 
Among the NHB blueberry cultivars harvested in Oregon in 2015, fruit firmness was higher in those harvested by hand compared to that by pneumatic shakers in 'Liberty', but lower in 'Draper' and 'Legacy' blueberry fruit (Table 2). The average bruised area and percentage of fruit with $>19 \%$ bruised was less in 'Draper' than in 'Legacy' and 'Liberty'. There was a slight difference in bruising due to shaking parameters, however, the percentage of sliced surface area indicating bruise damage was not affected by harvesting methods. Compared to $>25 \%$ bruise in blueberries harvested by the OTR harvester as previous studies have reported [4,7], pneumatic shakers and modified catching surface limited bruise damage to less than $8 \%$ (Table 2).

Table 2. Fruit firmness and bruise damage 'Draper', 'Legacy' and 'Liberty' northern highbush blueberries harvested by hand into a pail and with a hand held semi-mechanical shaker and fruit captured on a netted portable fruit catching frame. ${ }^{x}$

\begin{tabular}{cccc}
\hline Cultivar & Harvest Method & Fruit Firmness $(\mathbf{g} / \mathbf{m m})$ & \% Bruised Area \\
\hline \multirow{2}{*}{ Draper } & Hand & $220 \mathrm{~b}$ & $3.0 \mathrm{a}$ \\
& Shaker & $239 \mathrm{a}$ & $1.5 \mathrm{a}$ \\
\hline \multirow{2}{*}{ Legacy } & Hand & $166 \mathrm{~b}$ & $8.0 \mathrm{a}$ \\
& Shaker & $178 \mathrm{~b}$ & $10.0 \mathrm{a}$ \\
\hline \multirow{2}{*}{ Liberty } & Hand & $174 \mathrm{a}$ & $-\mathrm{z}$ \\
& Shaker & $152 \mathrm{~b}$ & - \\
\hline
\end{tabular}

${ }^{x}$ Fruit firmness was determined with a FirmTech II instrument. Bruise assessment was performed24 $\mathrm{h}$ after harvest by visual means to quantify the bruised area in fruit sliced through the equator. ${ }^{\mathrm{y}}$ Means within a column followed by the same letter are not significantly different at $p=0.05 .{ }^{\mathrm{z}}$ No data collected.

In 2016, we evaluated a semi-mechanical harvesting system consisting of a tractor-pulled harvest-aid platform with fruit catching surfaces (Figure 3), coupled with portable, hand-held, pneumatic shakers to detach fruit from several SHB and NHB blueberry cultivars (Table 3). Hitching the harvesting platform to a tractor eliminated the manual push-pull operation to move the platform down the plant row. The pneumatic shakers were operated with long and short nylon tines and at 310 and $454 \mathrm{KPa}$. Detached fruit was collected on suspended net and foam pad surfaces installed on the harvest-assist platform. Previous study on mechanical harvesting of SHB blueberries [7] showed that when 'Farthing' and 'Meadowlark' SHB plants were harvested with a commercial OTR harvester (Model 8000, Oxbo International, Lynden, WA, USA), marketable yield was significantly less and the percentage of fruit rated "soft" was significantly higher compared to hand harvested fruit.

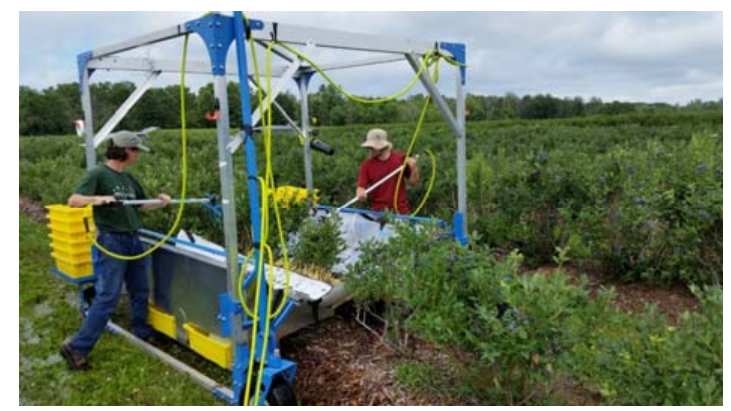

Figure 3. Harvesting blueberries with a semi-mechanical harvest-assist system consisting of hand-held pneumatic shakers to detach fruit and platforms to collect detached fruit. The frame is manually pulled/pushed over plants and the fruit catching platforms are pulled out while positioning the frame over the plants to be harvested and pushed towards each other to seal around the base of blueberry plants. Shown here are two workers harvesting blueberries with hand-held shakers. The yellow hoses carry pressurized air from a compressor to shakers. Yellow fruit lugs are positioned below the catching surface. The inclined catching surface diverted detached fruit into lugs. 
Table 3. The main effects of operating pressures of the hand-held fruit shaker and fruit catch surface materials installed on the harvest-assist platform on impact bruise in 'Draper' blueberry harvested by semi-mechanical harvesting system to detach fruit and modified fruit collecting surfaces in 2016 in Oregon.

\begin{tabular}{|c|c|c|c|}
\hline Treatment & Mean Bruised Area (\%) & $\begin{array}{l}\text { Percent of Fruit with } \\
>10 \% \text { Bruised }^{x}\end{array}$ & $\begin{array}{l}\text { Percent of Fruit with } \\
\quad>20 \% \text { Bruised }^{x}\end{array}$ \\
\hline \multicolumn{4}{|l|}{ Operating pressure (psi) } \\
\hline 0 (hand harvest) & $0.5 c^{y}$ & $0.0 \mathrm{c}$ & $0.0 \mathrm{c}$ \\
\hline 50 & $2.0 \mathrm{~b}$ & $6.5 \mathrm{~b}$ & $1.0 \mathrm{c}$ \\
\hline 60 & $3.4 \mathrm{a}$ & $13.5 \mathrm{a}$ & $5.2 \mathrm{~b}$ \\
\hline \multicolumn{4}{|l|}{ Catching surface material } \\
\hline Hand harvest & $0.5 \mathrm{~ns}$ & $0.0 \mathrm{~b}$ & $0.0 \mathrm{~ns}$ \\
\hline Foam pad & 2.6 & $9.5 \mathrm{~b}$ & 2.5 \\
\hline $\begin{array}{c}\text { Fabric net } \\
p>F \text {-value }\end{array}$ & 2.8 & $10.5 \mathrm{a}$ & 3.8 \\
\hline Operating pressure & 0.006 & 0.005 & 0.004 \\
\hline Catching surface material & 0.619 & 0.406 & 0.359 \\
\hline Pressure $\times$ Material & 0.660 & 0.278 & 0.359 \\
\hline
\end{tabular}

${ }^{x}$ Analysis was performed using ARCSIN (square root) transformed data; un-transformed lsmeans were presented in table. ${ }^{\mathrm{y}}$ Means within a column followed by the same letter are not significantly different at $p=0.05$. ns $=$ not significantly different at $p=0.05$.

In a preliminary study on three SHB cultivars ('Chickadee', 'Flicker' and 'Springhigh') (Table 4) bruise assessment evaluated the suitability of these cultivars for mechanical harvesting. In general, the fruit of 'Chickadee' and 'Flicker' developed less bruise damage than 'Springhigh'. The fruit of the latter cultivar is described as "soft" by the University of Florida blueberry breeding program [21] using sparkleberry as a genetic source for machine harvest traits for southern highbush blueberry. In addition, the study provided information about the effectiveness of two suspended fruit collecting surfaces in reducing mechanical impact damage. Also, it showed that fruit dropped from greater heights exhibited more impact damage.

Table 4. Determination of suitability of southern highbush blueberry cultivars ('Chickadee', 'Flicker', and 'Springhigh') for mechanical harvesting system consisting of hand-held shaker and harvest-assist platform. ${ }^{x}$

\begin{tabular}{cc}
\hline Treatment & Average Bruise Rating (\%) \\
\hline Cultivar & \\
Chickadee & $4.3 \mathrm{a} \mathrm{y}$ \\
Flicker & $4.3 \mathrm{a}$ \\
Springhigh & $6.7 \mathrm{~b}$ \\
Catching surface & \\
None/Hand harvest control & $2.2 \mathrm{a}$ \\
Metal sheet & $9.0 \mathrm{c}$ \\
Suspended foam pad & $3.7 \mathrm{~b}$ \\
Suspended woven fabric net & $4.1 \mathrm{c}$ \\
Drop height & \\
0 cm & $2.2 \mathrm{a}$ \\
$60 \mathrm{~cm}$ & $4.9 \mathrm{~b}$ \\
$90 \mathrm{~cm}$ & $6.3 \mathrm{c}$ \\
$p>$ F-value & \\
CV & 0.0682 \\
Surface & $<0.0001$ \\
CV $\times$ Surface & 0.5065 \\
Height & 0.0002 \\
Height $\times$ Surface & $<0.0001$ \\
CV $\times$ Height & 0.3679 \\
CV $\times$ Surface $\times$ Height & 0.0019 \\
\hline
\end{tabular}

$x$ The fruit collection surfaces were metal sheet riveted to the frame, and unsupported foam pad and woven fabric net positioned $6 \mathrm{~cm}$ above the metal sheet. Hand harvested fruit was dropped from heights of 60 and $90 \mathrm{~cm}$. ${ }^{y}$ Means within a column followed by the same letter are not significantly different at $p=0.05$. 
Harvesting of SHB blueberries ('Chickadee', 'Flicker', and 'Kestrel') by a semi-mechanical harvesting system with modified fruit collecting surfaces limited bruise damage to about $8.0 \%$ or less in all three cultivars (Tables 5-7). In contrast, in the fruit collected on the metal surface the bruise damage ranged from about 11 to $17 \%$ (Figure 4). Also, the percentage of fruit with several bruise damage (e.g., $>10 \%$ and $>20 \%$ of cut surfaces indicating damage) was quite high among the fruit collected on the metal surface in all three cultivars. Percentage of severely bruised fruit was relatively low in 'Chickadee' and 'Kestrel' blueberry when the fruit was collected on modified fruit collecting surfaces. In the case of 'Flicker' blueberry, impact damage was high even for fruit collected on softer, modified fruit collecting surface materials.

The study, however, showed that pneumatic shakers were not as efficient as hand picking in limiting the detachment of immature fruit in SHB blueberries. The percentage of green and red fruit comprised as low as $13 \%$ in 'Chickadee', but $42 \%$ in 'Kestrel' blueberry. At the time of harvest, it was estimated that about $70 \%$ of fruit on 'Chickadee' and 'Flicker' plants were ripe and ready for harvesting while in 'Kestrel' the ripe fruit comprised only $40 \%$ of fruit still on the plant.

Table 5. The influence of catching surface on bruising of 'Chickadee' blueberries harvested with harvest aide in 2016.

\begin{tabular}{cccc}
\hline Catching Surface & $\begin{array}{c}\text { Average Bruise Area } \\
\mathbf{( \% )}\end{array}$ & $\begin{array}{c}\text { \% Berries } \geq \mathbf{1 0} \% \\
\text { Bruised Area }\end{array}$ & $\begin{array}{c}\text { \% Berries } \geq \mathbf{2 0} \% \\
\text { Bruised Area }\end{array}$ \\
\hline Hand harvest & $1.2 \mathrm{a}$ x & $2.7 \mathrm{a}$ & $1.3 \mathrm{a}$ \\
Metal sheet & $10.9 \mathrm{~b}$ & $41.3 \mathrm{~b}$ & $24.0 \mathrm{~b}$ \\
Foam sheet & $2.9 \mathrm{a}$ & $8.0 \mathrm{a}$ & $2.7 \mathrm{a}$ \\
Net fabric & $2.8 \mathrm{a}$ & $6.7 \mathrm{a}$ & $4.0 \mathrm{a}$ \\
$p>$ F-value & $<0.0001$ & 0.0085 & 0.0222 \\
Surface & & & \\
\hline
\end{tabular}

${ }^{\mathrm{x}}$ Means within a column followed by the same letter are not significantly different at $p=0.05$.

Table 6. The influence of catching surface on bruising of 'Flicker' blueberries harvested with harvest aide in 2016.

\begin{tabular}{cccc}
\hline Catching Surface & $\begin{array}{c}\text { Average Bruise Area } \\
\mathbf{( \% )}\end{array}$ & $\begin{array}{c}\mathbf{\%} \text { Berries } \geq \mathbf{1 0} \% \\
\text { Bruised Area }\end{array}$ & $\begin{array}{c}\mathbf{\%} \text { Berries } \geq \mathbf{2 0} \% \\
\text { Bruised Area }\end{array}$ \\
\hline Hand harvest & $1.3 \mathrm{a}^{\mathrm{x}}$ & $2.7 \mathrm{a}$ & $0.0 \mathrm{a}$ \\
Metal sheet & $17.5 \mathrm{c}$ & $69.7 \mathrm{c}$ & $33.3 \mathrm{c}$ \\
Foam sheet & $5.5 \mathrm{~b}$ & $26.7 \mathrm{~b}$ & $9.3 \mathrm{~b}$ \\
Net fabric & $8.3 \mathrm{~b}$ & $30.7 \mathrm{~b}$ & $16.0 \mathrm{~b}$ \\
p F-value & $<0.0001$ & 0.0004 & 0.0018 \\
Surface & & 0.004
\end{tabular}

${ }^{\mathrm{x}}$ Means within a column followed by the same letter are not significantly different at $p=0.05$.

Table 7. The influence of catching surface on bruising of 'Kestrel' blueberries harvested with harvest aid in 2016.

\begin{tabular}{cccc}
\hline Catching Surface & $\begin{array}{c}\text { Average Bruise Area } \\
(\mathbf{\%})\end{array}$ & $\begin{array}{c}\text { \% Berries } \geq \mathbf{1 0} \% \\
\text { Bruised Area }\end{array}$ & $\begin{array}{c}\text { \% Berries } \geq \mathbf{2 0} \% \\
\text { Bruised Area }\end{array}$ \\
\hline Hand Harvest & $1.3 \mathrm{a}^{\mathrm{x}}$ & $2.7 \mathrm{a}$ & $1.3 \mathrm{a}$ \\
Metal Sheet & $10.9 \mathrm{c}$ & $52.0 \mathrm{c}$ & $25.3 \mathrm{c}$ \\
Foam sheet & $3.3 \mathrm{ab}$ & $12.0 \mathrm{~b}$ & $6.7 \mathrm{~b}$ \\
Fabric net & $5.4 \mathrm{~b}$ & $17.3 \mathrm{~b}$ & $9.3 \mathrm{~b}$ \\
$p>$ F-value & $<0.0001$ & 0.0008 & 0.0042 \\
Surface & & & \\
\hline
\end{tabular}

${ }^{\mathrm{x}}$ Means within a column followed by the same letter are not significantly different at $p=0.05$. 


\title{
Control
}

\section{Metal \\ surface}

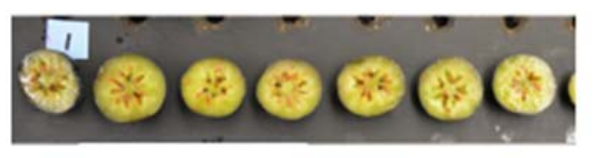

\section{No bruised fruit}

\section{Foam pad (unsupported)}

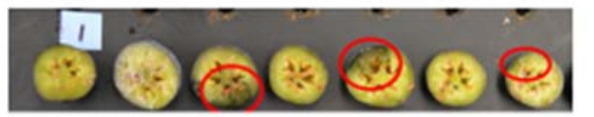

Many are bruised

\author{
Net fabric
}

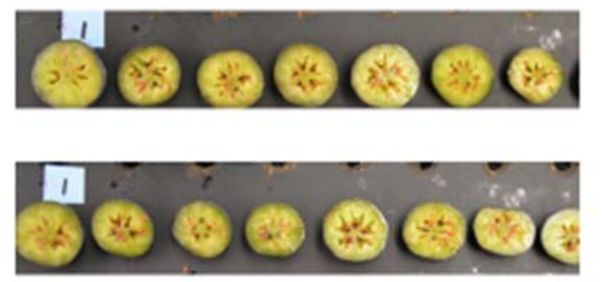

No bruised fruit

No bruised fruit

Figure 4. The effect of fruit catching surface on extent of bruise damage in the fruit of southern highbush blueberry 'Flicker'. Fruit was harvested by hand (Control) and semi-mechanical harvesting system using a harvest-assist platform. Hand harvested fruit was dropped into a 5-L plastic pail. With the semi-mechanical system, fruit was detached with a hand-held 'Golia' olive shaker and detached fruit landed on platform's metal surface or onto a pad or net fabric suspended over the metal surface. A fruit damage by impact was initially indicated by water soaked tissues and then after about $1 \mathrm{~h}$ the damaged area turned darker (circled in red).

\subsection{Modification of Fruit Catching Surface}

Modifying the fruit collection surfaces using suspended foam sheet and woven net fabric (Figure 5) significantly reduced impact (Figure 6). BIRD sensor recorded impact values $>200 \mathrm{~g}$ when it dropped even from a height of less than $30 \mathrm{~cm}$. Glued-on foam sheet over the metal surface reduced impact slightly, but as the drop height increased to nearly $45 \mathrm{~cm}$, the impact value reached $200 \mathrm{~g}$. A significant reduction in impact was achieved by the two modified fruit collecting surfaces used in the study. The suspended foam sheet maintained impact value to $<200$ even when the drop height was increased to $1.2 \mathrm{~m}$. The lowest impact values were recorded on the suspended woven net fabric.
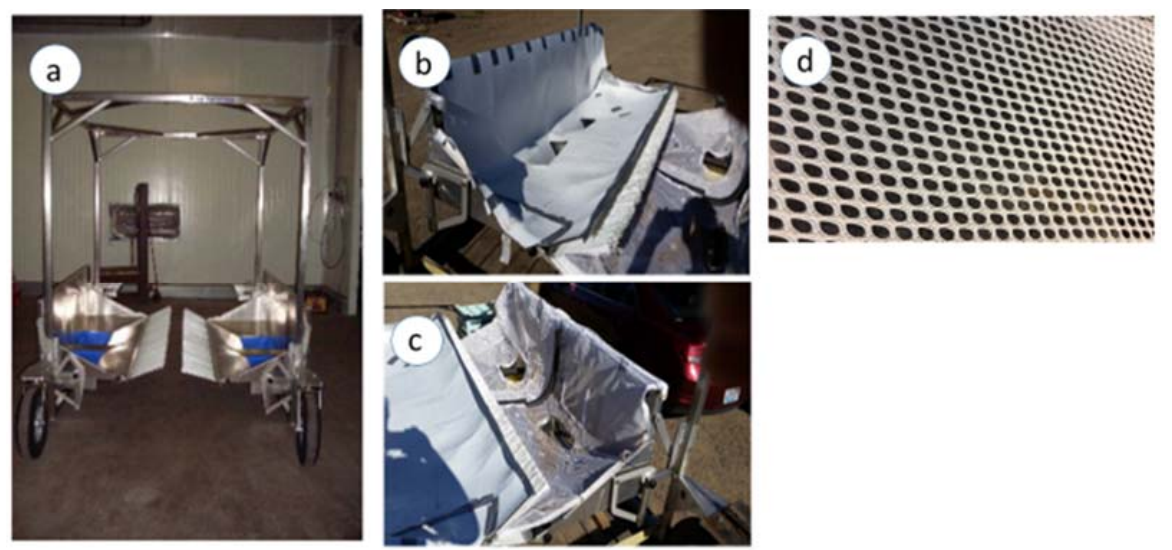

Figure 5. Harvest-assist platform for semi-mechanical harvesting of blueberries. (a) A harvest-assist platform (BBC Technologies, Fresno, CA, USA) shown with left-side and right-side stainless steel fruit catching surface and brush bristle in the middle to seal around individual blueberry plants; (b) A close-up of the modified fruit catching surface constructed with foam pad installed about $3 \mathrm{~cm}$ over the stainless steel surface; (c) Shown is a woven net fabric suspended over the other catching surface; (d) A close of the netted woven fabric installed on one side of the harvest-assist platform. 


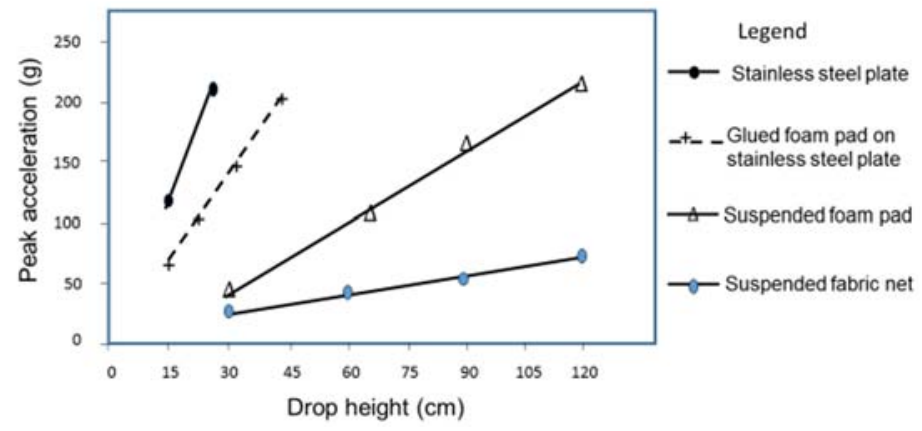

Figure 6. The relationship between impact levels and contact surface materials. The BIRD sensor was dropped on four different contact surface materials installed on the harvest-assist platform: Stainless steel plate, foam pad glued onto the stainless steel plate, unsupported foam pad installed over the stainless steel plate, and woven net fabric suspended over the stainless steel plate. Data points are the means of 10 recordings by the BIRD sensor for each drop height and only the first impact of each drop was collected for further data analysis. The BIRD sensor recorded impacts in three orthogonal directions. The largest acceleration value from each of the $x, y$, and $\mathrm{z}$ accelerometers captured during the first impact was summed to calculate the peak acceleration. Peak acceleration reflects the magnitude of the impact.

\subsection{Vibration to Blueberry}

Amplitude analysis of vibration transmitted from the shaking equipment (e.g., Golia olive shaker) through the limb to BIRD sensors attached at three different distances was performed (Figure 7). The findings indicated that the vibration amplitude was highest near the shake site and decreased gradually. The amplitude at the top section of the limb was only $30 \%$ of that recorded at the bottom section which was closest to the engagement point. Higher amplitude of vibration was recorded with increasing operating pressure for the shaker. It was also observed that when a large diameter limb was shaken much lower levels of vibration were recorded at all three locations along the limb.

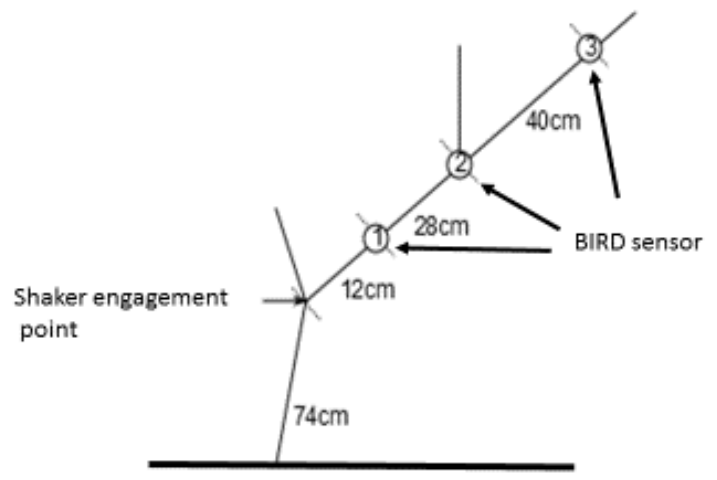

Figure 7. A drawing of the blueberry cane denoting the locations of BIRD sensor attachments and where the pneumatic shaker engaged the plant.

\subsection{Ergonomic Study}

Ergonomic evaluation by electromyography (EMG) was conducted on workers operating the portable, hand-held blueberry harvesting equipment (Figure 8). In this study, muscle activity $(\mu \mathrm{V})$ was recorded with electrode sensors attached at seven upper body regions locations (left and right forearms, biceps, shoulders, and lower back (Figure 9). EMG results showed that the forearm and bicep muscles experienced the least amount of strain regardless of the operating posture (e.g., measured $\mu \mathrm{V}$ output of $<60$ ). The only exception was with the BEI H1 berry stripper held high above the shoulders. The high posture activated the forearm muscles, especially with the heavier BEI shaker. The overhead 
posture activated the lateral deltoid muscles as well with the heavier BEI shaker generating greater EMG than lighter shakers. The highest muscle activity was recorded in the lower back region. When the shakers were operated in a bent position, EMG registered well above $1600 \mu \mathrm{V}$ compared to about $1000 \mu \mathrm{V}$ operating the shaker in standing, high, and overhead operating postures.

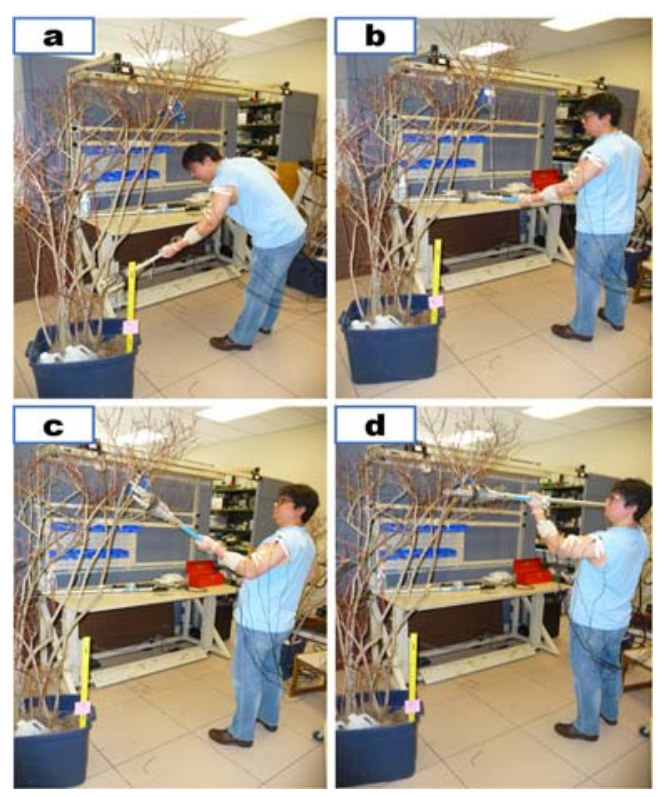

Figure 8. Ergonomic evaluation of portable hand-held shaker used for harvesting blueberries. Muscle activity was measured using electromyography. The electrode sensors were attached on multiple body regions: Forearm, upper arm, shoulder, and lower back. The shaker was operated with the operator in bent (a), standing (b), arched backward (c), and standing (d) postures.
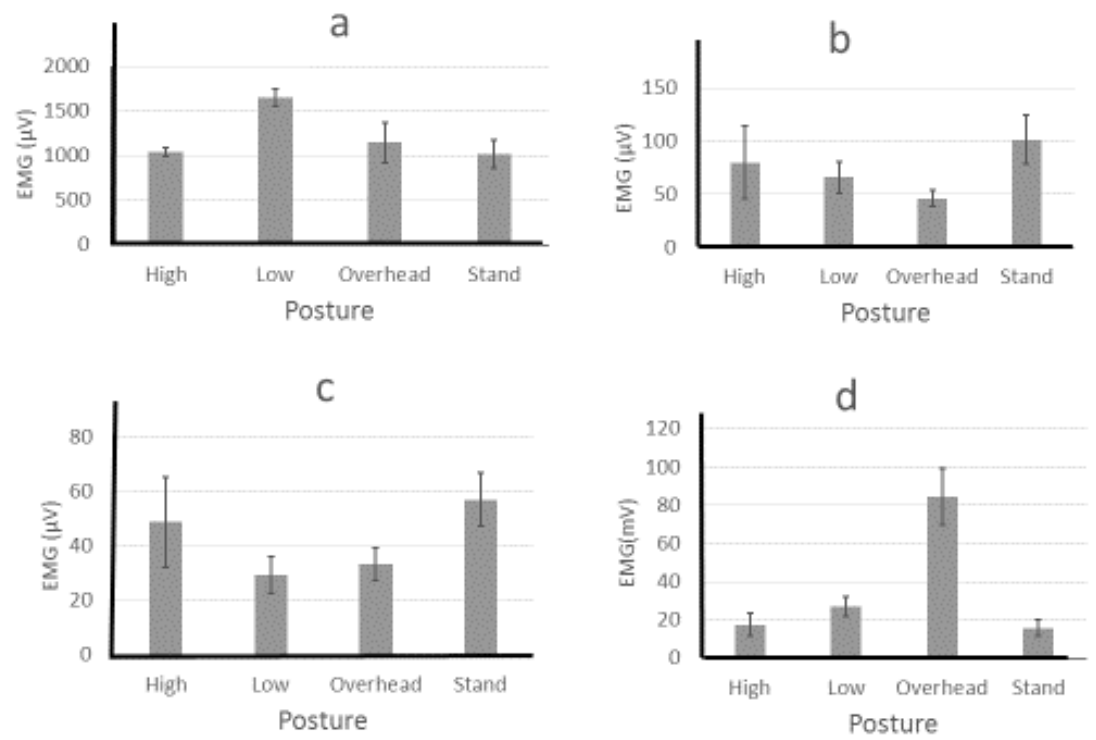

Figure 9. Muscle activity measured by electromyography as EMG $(\mu \mathrm{V})$ was recorded by electrode sensors attached to the lower back (a), bicep (b), forearm (c), and shoulder (lower deltoid) (d) while human subjects operated a hand-held blueberry shaker in four postures: High (arched back with shaker head above shoulder height), Low (bent at waist with shaker head below waist), Overhead (straight back with both arms raised), and Standing (straight back and shaker at waist height). The vertical lines at the top of the bars represent the standard error of the mean. 
In another study, both light-weight and heavier shaking equipment were tethered to the harvesting platform with a tool balancer which showed that the heavy equipment with a support balancer required the minimum effort and it had less workload then the untethered light-weight shaking equipment.

EMG data were used to perform rapid upper limb assessment (RULA) for operating postures and weight of shaking equipment. RULA assists in determining the potential risk for work-related musculoskeletal disorders (WRMSDs) for operating hand-held shakers for harvesting blueberries. A RULA score of 5 to 6 indicates that design changes are required and a score from 3 to 4 warrants further investigation. A score of $>6$ indicates that the operating posture and equipment usage should discontinue and strongly suggests that necessary modification to the equipment and/or operating technique is a prerequisite to reducing unacceptable level of physiological and biochemical workload imposed on the operator. The results of RULA analysis showed that when light-weight shaker was operated without tethering it to the platform the RULA score for both upper limbs was 6. By tethering the light- and heavy-weight shakers to the platform with a tool balancer, the RULA score dropped to 4 or less.

Hand-held blueberry harvesting equipment is operated with a quick push-pull motion with the shaking head engaging the blueberry plant in about a 1-s pulsing action. From the RULA postural analysis, lower score was obtained when using a heavy shaker that was tethered to the platform, no difference was observed between pushing and pulling motions. Vibration data from BIRD II sensor attached to the handle showed that the heavy shaker, if tethered to the harvesting platform, transmitted less vibration to operator's hands than untethered light-weight shaker. A simple shocking absorbing pad wrapped on the handle reduced the vibration on the hand from the shaking head was transmitted through the handle to operator's left and right hands.

\section{Discussion}

\subsection{Mechanical Harvesting System}

According to Brown et al. [4], 78\% of the blueberry harvested by commercial mechanical harvesters had severe bruise damage compared to only $23 \%$ in hand harvested fruit. The results of this study clearly showed that harvesting blueberries with hand-held shakers and capturing detached fruit on softer surfaces was gentler than OTR harvesters and resulted in less bruise damage. Still, more technological improvements are needed to increase harvest capacity, reduce bruising, limit percent ground loss of fruit, and reduce detachment of immature (green or red) fruit. In addition to these key technical limitations, OTR mechanical harvesters $(\sim \$ 140,000$ to $\$ 240,000)$ are generally not affordable to small- and medium-sized growers. In some of the major blueberry producing states such as Oregon [22], Florida [23], and North Carolina [24], the average blueberry farm is less than 20 hectares in size.

As an alternative to hand harvesting, portable hand-held shaking devices (e.g., $\mathrm{H}$ model, BEI Inc., South Haven, MI, USA [24] and pneumatic limb shaker (Campagnola SRL, Bologna, Italy) have been used to harvest fresh market quality fruit onto a small, manually positioned catch frame [15-17]. However, the hand-held shaker such as the $\mathrm{H} 1$ berry stripper which weighs $\sim 2.4 \mathrm{~kg}$ has two major problems that limit its adoption: low harvest capacity and potential worker fatigue and injury. The H-model hand-held shaker is powered by electromechanical or pneumatic system and is quite heavy. The workers must position the catch frame under the plant, move the battery or air compressor, shake the fruit from the plant, and then handle the fruit collection box or have other workers maneuver the catch frame and collection boxes, and then move the battery or compressor. Field observations indicated that the workers are actively engaged in an assigned task of fruit harvesting less than half of the time. Thus, the pace of fruit harvesting is slow and tedious when a portable fruit catching frame is used. In addition, the workers can easily get fatigued by operating the handheld shaker because of vibration and the weight of the shaker and other laborious operations such as constantly moving the catch frame and handing empty and filled lugs. It is well documented that any repetitive job 
having potentially excessive frequencies, high forces and poor limb postures resulted in work-related musculoskeletal disorders (WRMSDs) [19]. In agricultural work, WRMSDs have accounted for over 60,000 lost-time injuries on U.S. farms. Hand and wrist problems were a significant proportion of these injuries [20]. Due to these limitations, the handheld shaker devices such as the BEI H-Model have not been widely adopted among blueberry growers. For instance, a recent survey of the blueberry industry in Oregon showed that only $10 \%$ of growers had used handheld shakers and many expressed that their experiences with them was not favorable. Harvest inefficiency and fatigue after prolong use of hand-held shakers contributed to their decision to discontinue the use of portable, hand-held shakers.

The new harvesting method can potentially reduce labor requirement to less than 100 hour/hectare/year and help to mitigate the rising labor cost and shortage of workers for harvesting currently faced by the blueberry industry. The semi-mechanical system studied here harvested high quality blueberries with little or no damage, and the fruit was acceptable for the fresh-fruit market even after several weeks in cold storage. The semi-mechanical harvesting platform (Figure 5) is expected to cost about $\$ 11,000$ for a tractor-pulled unit (BBC Technologies, Fresno, CA, USA) and up to $\$ 60,000$ for a self-propelled unit with powered fruit conveyance system (GK Machine, Donald, OR, USA). The system is scale neutral and its performance will be especially appealing to small- and medium-size growers.

\subsection{Designing Mechanical Harvesters to Reduce Impact Damage}

In terms of mechanical impact to blueberry fruit, research has shown that softening and bruise damage in machine-harvested fruit can be reduced if the drop height can be maintained at less than $30 \mathrm{~cm}$ [4]. The V45 blueberry harvester (BEI; South Haven, MI, USA) had design features to minimize drop height, and reduce ground loss [13]. However, the V45 blueberry harvester has not been widely accepted commercially and by 2005 all V45 blueberry harvesters sold about 10 years earlier were retro-fitted with two vertical rotary or slapper fruit shakers [9]. Other problems with mechanical harvesting of blueberries have stimulated innovations in cultural practices for improving machine harvest efficiency. These practices are focused primarily on minimizing ground loss and reducing the number of mature fruit missed by the machine $[9,13,21]$. Strik and Buller [25] in Oregon showed that supporting 'Bluecrop', an NHB blueberry, with a simple two-wire trellis system increased harvest efficiency significantly, mainly by reducing the number of mature fruit missed by the machine. The maximum proportion of fruit remaining after the last machine harvest was reduced $30.8 \%$ in non-trellised plots to $15.5 \%$ in trellised plots with canes kept more upright by trellis wires.

Blueberry growers are interested in using mechanical harvesting equipment for harvesting blueberries destined for fresh market because of financial and labor concerns [22-24]. Breeders are considering bush architecture, ease of detachment of mature fruit but not immature fruit, loose fruit clusters, small, dry-stem scar, firm fruit, and a concentrated ripening period to develop cultivars suitable for machine harvest [21]. In this study, the research focused on machine harvesting commercially grown SHB and NHB blueberry cultivars. Hand-held, powered olive shakers and modified collecting surface materials (Figures 3 and 5) were used together with a harvest-assist platform in an attempt to increase harvest capacity, fruit removal efficiency, and maintaining fruit quality. Several blueberry cultivars were identified to be suitable for harvesting by this mechanically-assisted fruit picking system. Based on high bruise potential and low harvest efficiency, 'Springhigh' and 'Kestrel' SHB blueberries, respectively, were not suitable for machine harvest. Among the NHB blueberries reported here 'Draper' and 'Legacy' appear to be good candidates for further investigation.

The harvesting system used in this study appears to be a promising platform for further mechanization effort. An international blueberry harvesting equipment manufacturer has incorporated a number of harvesting system components developed in this study into a self-propelled ORT harvesting platform (e.g., Model 7420, Oxbo International, Lynden, WA, USA). This harvesting equipment will be used in 2017 and 2018 season in major blueberry producing states (e.g., FL, CA, $\mathrm{OR}$, and WA, USA). Additional design changes in the harvesting system, such as an improved fruit 
decelerating, intermediate fruit catching surface, are being incorporated into the Model 7420 blueberry harvester (Figure 10). On the modified OTR harvester, the hard catch plates have been replaced with patent-pending plates with soft surfaces to reduce impact damage. Additional collection/deflection surfaces have been mounted $30 \mathrm{~cm}$ above the catch plates to decrease drop height and prevent detached fruit from directly falling $>1 \mathrm{~m}$ onto catch plates and conveyance belts located below. The powered conveyance system has eliminated the need to manually handle harvested fruit, as is the case with current harvest-assist platforms.

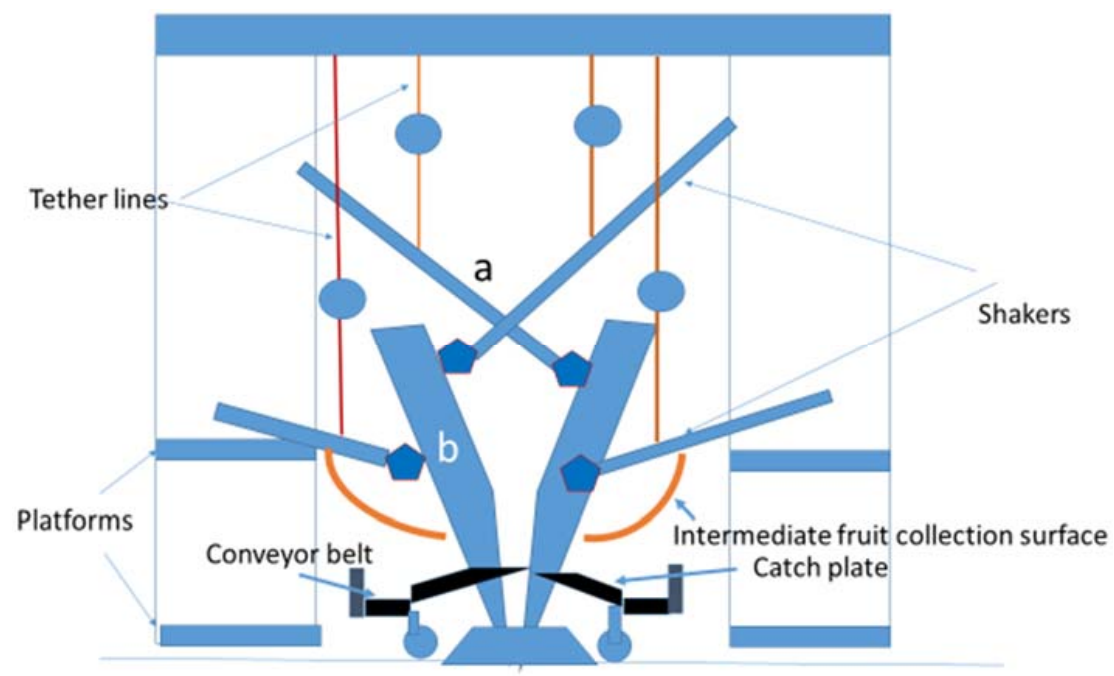

Figure 10. A drawing of the proposed mobile, semi-mechanical blueberry harvesting platform with hand-held shaker (a) tethered to the platform. The harvesting platform will have two levels on each side to position shaker operators. The lower level for the operator to engage the lower section of the blueberry plant (b) and the upper level for engaging the upper portion of the plant. Stool seats (not shown) will be installed on the platforms for workers to set and operate the shakers that are tethered to the harvesting platform with a tool balancer. The detached fruit is collected on the intermediate fruit collecting surface and soft catch plates. Decelerated fruit will roll onto the conveyor belt and transferred to fruit lugs.

\subsection{Needs to Reduce Work-Related Musculoskeletal Disorders}

Ergonomic analysis suggested that more modifications are required on harvesting equipment, and also how workers use hand-held equipment to reduce potential work-related musculoskeletal disorders. A self-propelled, mobile, harvest-assist platform is envisioned for future studies(Figure 10). The platform will have two levels for operators to work the shaking equipment. The worker positioned on the upper level can engage the upper half of the plant canopy while the worker at the lower level engages the lower half of plant canopy. This worker configuration would reduce the need to raise the shaker above the shoulders (Figure 8). A Stool seat can also be installed on each platform allowing workers to set and be positioned lower in relation to the plant and minimize the need to bend. Properly positioning the worker relative to the blueberry plant could contribute to relieving muscle strain prevent and potentially reduce WRMSDs in workers operating blueberry harvesting equipment. For continuous operation of harvesting equipment, it appears that having the harvesting equipment tethered to the platform with a tool balancer is an important consideration.

\section{Materials and Methods}

\subsection{Study Site and Harvesting System Descriptions}

In 2015 summer, a preliminary blueberry harvesting study was conducted in Oregon (OR) using mature plants of northern highbush (NHB) blueberry plants ('Draper', 'Legacy', and 'Liberty'), most 
widely grown cultivars in the Pacific Northwest. For semi-mechanical harvesting method, a pneumatic (air-powered) Campagnola 'Golia' olive shaker (Brewt Power Systems, Merced, CA, USA) was used to detach fruit (Figure 2). Two different tines (10-cm-long and 20-cm-long) were installed into the head of a Golia shaker. The shaker was operated at $45 \mathrm{psi}(310 \mathrm{KPa})$ or $65 \mathrm{psi}(454 \mathrm{KPa})$. Two portable frames constructed of metal pipes and lined with netting (Haven Harvesters, South Haven, MI, USA) were placed around the base of the plants for collecting the detached fruit (Figure 2). Fruit collected on the net were manually poured into lugs. Semi-mechanical shaking time ranged from 1 to $6 \mathrm{~min}$ to harvest each of 4 plants for a given treatment. Hand-harvested plots were manually hand harvested for $5 \mathrm{~min}$. Hand-harvested fruit were gently dropped into a 4-L plastic pail. In both hand and semi-mechanical harvesting methods, the harvested fruit from four replicate plots were weighed and sorted into blue, and red/green categories (Figure 11). The fruit in each category were weighed to calculate the percentage of green, red, and blue fruit. For comparison of fruit quality with those harvested with an OTR harvester, 'Draper' fruit harvested by a rotary harvester (Littau Harvester, Stayton, OR, USA) were included in the analysis.

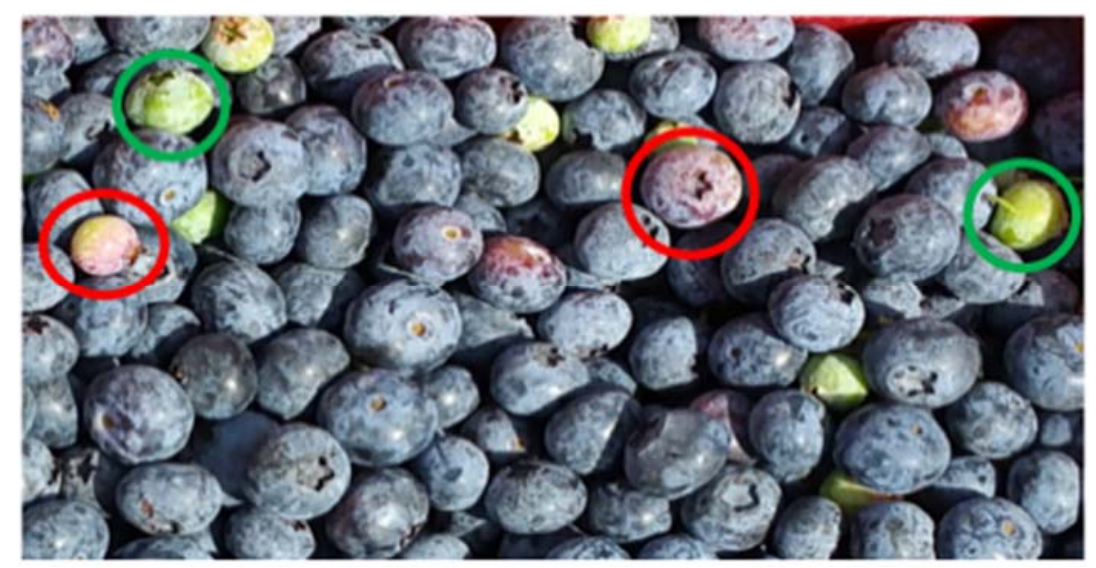

Figure 11. The fruit harvested by the experimental semi-mechanical harvesting system prior to sorting. Fruit consisted mostly of blue-colored fruit and some green-colored (shown circled in green) and red-colored (shown circled in red) fruit. The latter two categories are culled manually and by electronic sorting machines on the packing line and only the blue-colored fruit are packaged. Occasionally, machine-harvested fruit have over-ripe and smashed berries (not shown).

Twenty-five blue-colored fruit per plot were used to determine fruit firmness using aFirmTech II (BioWorks, Inc., Wamego, KS, USA), and frozen for later analysis of total soluble solids ( ${ }^{\circ}$ Brix) and total titratable acidity (TAA) determinations. Blue fruit for cold storage were poured into clamshells and placed in a cold room maintained at $1{ }^{\circ} \mathrm{C}$ for 6 weeks. Fruit damage and quality evaluation was performed 1 day after harvest and after 6-week cold storage, plus 1 day at room temperature using the methods previously described for fruit evaluation $[4,7,11,12]$. Fruit were sliced through the equator with a razor blade and the bruised area was estimated from cut surface area indicated by tissue discoloration (Figure 4).

\subsection{Study Sites and Harvesting System Descriptions}

In 2016, blueberry harvesting studies were conducted in Florida (FL) and Oregon (OR). In FL, three southern highbush (SHB) blueberry cultivars (Chickadee, Flicker, and Kestrel), recently released blueberries from the University of Florida blueberry breeding program were either hand harvested or harvested with a semi-mechanical harvesting system (Figures 3 and 9). In Oregon, the NHB cultivar Draper was harvested by hand or with a semi-mechanical harvesting system (Figure 9). The pneumatic olive shaker was operated at either 50 or $60 \mathrm{psi}$ and the platform was set up with an unsupported foam sheet on one side and with a net fabric suspended over the platform frame on the other side (Figure 9). 
Harvested fruit was weighed and sub-samples were taken from each harvested plot and sorted into green-, red-, and blue-colored fruit. Fifty blue fruit from each plot were held at room temperature for $24 \mathrm{~h}$ and then tested for firmness using a FirmTech II instrument and sliced through the equator to assess for bruise damage (Figure 4). Bruise assessment consisted of slicing the fruit along the equator and photographing the sliced fruit. The images were used to estimate the discolored area (\% of cut surface area with bruise damage) by two evaluators $[4,7,11,12]$.

\subsection{Impact Measurements, Blueberry Drop Tests and Bruise Evaluation}

The mechanical impacts generated by fruit catching surfaces were measured with the BIRD (berry impact recording device) sensor [10-12]. The BIRD sensor is a microcontroller-based data logger and measures mechanical impacts using a tri-axial accelerometer (Figure 12). The sensor has been miniaturized to a size and weight approaching a very large blueberry fruit, and it has the sufficient sensing range and precision to measure the impacts generated on the packing lines and by harvesting equipment. It has an internal memory and power supply, enabling it to be operated independently in the field to quantify mechanical impacts. The BIRD sensor records impacts in three orthogonal directions with sensing range of $\pm 346 \mathrm{~g}$ (gravitational acceleration, $g=9.8 \mathrm{~m} / \mathrm{s}^{2}$ ) in the vector summation and maximum $2 \mathrm{kHz}$ sampling frequency. One mechanical impact recorded by the BIRS sensor resembles a bell curve shape. The maximum acceleration value of the impact is considered the peak acceleration [10-12]. PeakG which is the largest summation acceleration in one impact curve and directly reflects the magnitude of the impact [12].

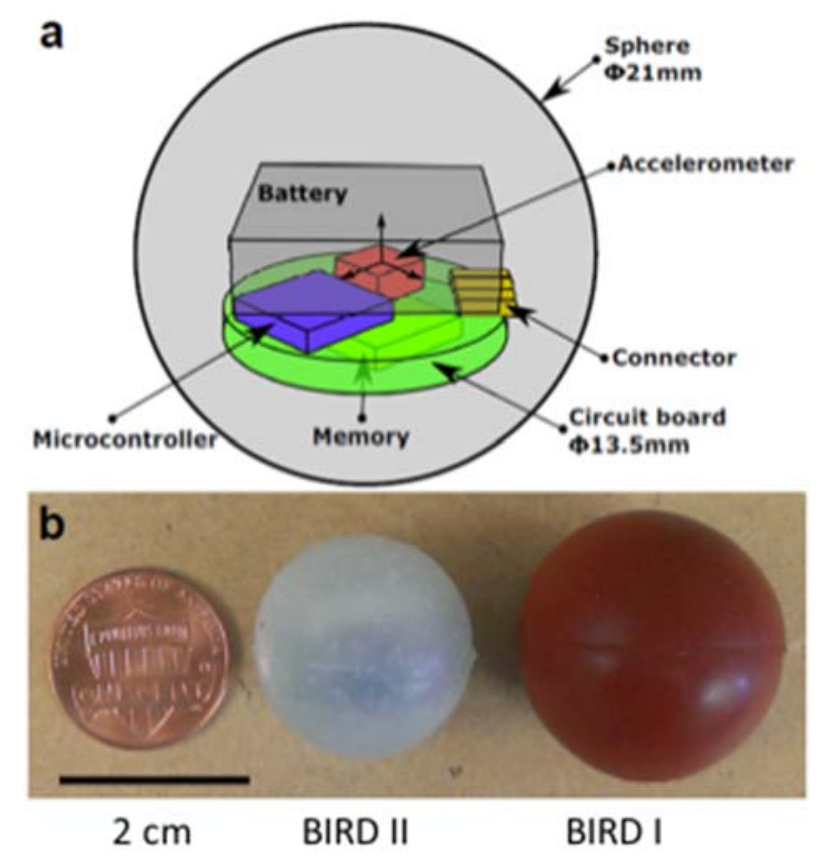

Figure 12. The blueberry impact recording device (BIRD) sensor (a). The electronic circuit board was cast in silicon rubber. The BIRD II sensor (b) used in this study is a an instrumented sphere with a diameter of $22 \mathrm{~mm}$ and mass of 6 grams and housing a microcontroller-based data logger which measures mechanical impacts in three orthogonal directions with a tri-axial accelerometer with sensing range of $\pm 346 \mathrm{~g}$ (gravitational acceleration, $g=9.8 \mathrm{~m} / \mathrm{s}^{2}$ ) in the vector summation and maximum of $2 \mathrm{KHz}$ sampling frequency. The sensor was fully calibrated using a centrifuge and an impact table. The accuracy of the sensor was between $0.50 \%$ and $0.63 \%$ and the precision error was within $0.06 \%$ to $0.23 \%$. For size comparison, the BIRD II sensor placed alongside a US penny coin (left) and the original BIRD I sensor (right). 
The drop test consisted of dropping the BIRD sensor 7 times onto the metal surface of the harvest-assist platform (BBC Technologies, Fresno, CA, USA) and two suspended fruit catching surfaces (Figure 8), consisting of $6.35 \mathrm{~mm}$ thick 'No Bruze' foam sheet (PORON Urethane Foam, Rogers Corporation, Woodstock, CT, USA) or 0.8-mm-thick woven net fabric (Haven Harvester, South Haven, MI, USA) from heights of 15, 30, 60 and $90 \mathrm{~cm}$. Four replicates of 50 hand-harvested berry samples of 'Chickadee', 'Draper', 'Flicker', and Kestrel' were dropped individually onto the metal surface and suspended surfaces. Dropped fruit was placed in a clamshell and held at $21^{\circ} \mathrm{C}$. For each genotype, additional 50 fruits were transferred into a clamshell and served as control samples. After $24 \mathrm{~h}$, both the dropped and control berries were sliced through the equator and photographed. Afterwards, two evaluators read the images of the sliced fruits along the equator for surface area of discolored zones and estimated the discolored area (\% of cut surface area with bruise damage), following the protocol described by Brown et al. [4].

\subsection{Shaker Tests}

In a field test, energy transfer from the shaker to various parts of blueberry plants was determined with the BIRD sensor. One tall fruit-bearing cane was selected on 4 mature blueberry plants. BIRD sensors were attached to the cane at 3 positions (bottom, middle, and top) with electrical tape (Figure 5). The canes were shaken one at a time with a Golia olive shaker and hook shaker that engaged the cane just below the location of the bottom sensor at $50 \mathrm{psi}(344 \mathrm{KPa}), 80 \mathrm{psi}(551 \mathrm{KPa})$, and $110 \mathrm{psi}$ $(758 \mathrm{KPa})$. After recording the acceleration the maximum acceleration of each pulse was calculated and the average and standard deviation of the maximum acceleration was tabulated.

\subsection{Ergonomic Studies}

Ergonomic analyses used in this study were previously utilized in analyzing appleharvesting [26-28]. An independent comparison of hand vs. semi-mechanical harvesting was performed utilizing a number of physiological approaches: electromyograms (EMG), rapid upper limb assessment (RULA) was conducted for estimating the postural risks of work-related upper limb injury [29]. EMG is a measure of the electrical activity of a muscle that is directly proportional to the force being produced by the muscle [30]. The EMG signal from four specific muscles was recorded with a Flex-Comp Infiniti physiological recording system (NexGen Ergonomics): trapezius and latissimus dorsi for shoulder strain and the flexor digitorum profundus and superficialis for forearm strain. Heart rate was recorded with a Polar Heart Rate Monitor and checked to see if it was within reasonable levels according to the Brouha criteria and monitor heart rate creep which indicated fatigue [31]. Again, these measurements were taken on several workers in a laboratory setting and at two field sites. Electrode sensors were attached on multiple body regions: Forearms, upper arms, shoulders, and lower back. The shaker was operated with the operator in bent with hands holding the shaker below waist, standing with shaker held at waist height, high with hands at shoulder height, and overhead postures with hands over the shoulder height and lifting the shaker (Figure 11). The shakers used in the ergonomic analysis included the Campagnola 'Golia' olive shaker with long or short tines (Figure 2), attached to a long handle that weighed $2 \mathrm{~kg}$. The BEI H1 berry stripper was attached to a long handle and weighed $4 \mathrm{~kg}$ as shown in Figure 6. Also, a Campagnola hook shaker on a long pole [17] that weighed $1.5 \mathrm{~kg}$ (not shown) has been evaluated in Chile for harvesting blueberries.

\subsection{Statistical Analysis}

Data were analyzed by using SAS General Linear Model analysis of variance (ANOVA) (SAS Institute, Cary, NC, USA) procedure to summarize the data. When differences were detected at $p \leq$ 0.05 , the data were subjected to mean separation by differences of least-square means using SAS Proc Mixed (SAS v. 9.1, SAS Institute, Cary, NC, USA). 


\section{Conclusions}

The semi-mechanical, platform-based harvest aid system performed reasonably well in terms of harvested amount, detachment selectivity, and quality of fruit after harvest and storage. In some cultivars, the fruit harvested by semi-mechanical harvesting system was as good as that harvested by hand and maintained good quality in cold storage. The semi-mechanical harvesting system offers the following benefits: (1) Improved harvest efficiency compared with hand-harvest. The workers do not need to position the catch frame under the plant, move the air compressor, shake the fruit off the plant, and then handle the fruit collection box. Because of the elimination of these steps, harvest efficiency is expected to be improved 10-20 times compared with hand-harvest; (2) Reduced fatigue because the workers do not need to support the full weight of the shaker all the time. The study showed that a number of refinements in shaker design and operating protocol are required for maintaining the well-being of workers who will operate hand-held harvesting equipment for hours, instead of minutes, on the mobile, harvesting platform.

\section{Future Perspectives}

A harvesting system consisting of portable pneumatically-powered portable shakers and collecting the detached fruit on soft fruit catching surfaces and conveyance belts mounted on a mobile platform is promising.

Acknowledgments: This work was financially supported by the U.S. Department of Agriculture, National Institute of Food and Agriculture, Specialty Crop Research Initiative research program (Award No.: 2014-51181-22383). The authors would like to acknowledge Scott Wolford, Renee Allen-Holland, Ann Rose, Jedediah Smith, Heather Andrews, Eric Ostmark, Eunsik Kim, and Adrian Berry for assistance with equipment fabrication, ergonomic analysis, field and laboratory work, and fruit quality assessment.

Author Contributions: F.T., W.Q.Y., C.L., and A.F. conceived and designed experiments; F.T., R.X., J.W., S.S., K.S., and B.H. performed the experiments and collected data; F.T., W.Q.Y., R.X., A.F., K.S., S.S., and B.H. analyzed the data; and F.T. wrote the paper.

Conflicts of Interest: The authors declare no conflict of interest.

\section{References}

1. Statistics Division FAO of the United Nations. Crops (Production). 2015. Available online: http:/ /www.fao. org/faostat/en/\#data/QC/visualize (accessed on 15 January 2017).

2. Eklund, B. 2014 Blueberry Statistics; National Agricultural Statistics Service, United States Department of Agriculture: Washington, DC, USA, 2016; p. 9. Available online: http:/ /www.nass.usda.gov/Statistics_by_ Subject/result.php?B31557DC-DDD9--3C5D-9FA2-C7F176ADE896sector=CROPSgroup=FRUIT (accessed on 15 January 2017).

3. Brazelton, C. 2014 World Blueberry Statistics and Global Market Analysis; U.S. Highbush Blueberry Council: Folsom, CA, USA, 2015; p. 105.

4. Brown, G.K.; Schulte, N.L.; Timm, E.J.; Beaudry, R.M.; Peterson, D.L.; Hancock, J.F.; Takeda, F. Estimates of mechanization effects on fresh blueberry quality. Appl. Eng. Agric. 1996, 12, 21-26. [CrossRef]

5. Dale, A.; Hanson, E.J.; Yardborough, D.E.; McNicol, R.J.; Stang, E.J.; Brennan, R.; Morris, J.R.; Hergert, G.B. Mechanical harvesting of berry crop. In Horticultural Reviews; Janick, J., Ed.; AVI Publishing: Westport, CT, USA, 1996; Volume 16, pp. 255-382.

6. Mehra, L.K.; MacLean, D.D.; Savelle, A.T.; Scherm, H. Postharvest disease development on southern highbush blueberry fruit in relation to berry flesh type and harvest method. Plant Dis. 2013, 97, $213-221$. [CrossRef]

7. Takeda, F.; Krewer, G.; Li, C.; MacLean, D.; Olmstead, J.W. Techniques for increasing machine-harvest efficiency in blueberries. HortTechnology 2013, 23, 430-436.

8. Van Dalfsen, K.B.; Gaye, M.M. Yield from hand and mechanical harvesting of highbush blueberries in British Columbia. Appl. Eng. Agric. 1999, 15, 393-398. [CrossRef] 
9. Takeda, F.; Krewer, G.; Andrews, E.L.; Mullinix, B.; Peterson, D.L. Assessment of the V45 blueberry harvester on rabbiteye and southern highbush blueberries pruned to V- shaped canopy. HortTechnology 2008, 18, 130-138.

10. Yu, P.; Li, C.; Takeda, F.; Krewer, G.; Rains, G.; Hamrita, T. Measurement of mechanical impacts created by rotary, slapper, and sway blueberry mechanical harvesters. Comput. Electron. Agric. 2014, 101, 84-92. [CrossRef]

11. Yu, P.; Li, C.; Takeda, F.; Krewer, G. Visual bruise assessment and analysis of mechanical impact measurement in southern highbush blueberries. Appl. Eng. Agric. 2014, 30, 29-37.

12. Xu, R.; Takeda, F.; Krewer, G.; Li, C. Measure of mechanical impacts in commercial blueberry packing lines and potential damage to blueberry fruit. Postharvest Biol. Technol. 2015, 110, 103-113. [CrossRef]

13. Peterson, D.L.; Wolford, S.D.; Timm, E.J.; Takeda, F. Fresh market quality blueberry harvester. Trans. Am. Soc. Agric. Eng. 1997, 40, 535-540. [CrossRef]

14. Peterson, D.L.; Brown, G.K. Mechanical harvester for fresh market quality blueberries. Trans. Am. Soc. Agric. Eng. 1996, 39, 823-827. [CrossRef]

15. Casamali, B.; Williamson, J.G.; Kovaleski, A.P.; Sargent, S.A.; Darnell, R.L. Mechanical harvesting and postharvest storage of two southern highbush blueberry cultivars grafted onto Vaccinium arboretum rootstocks. HortScience 2016, 51, 1-8. [CrossRef]

16. Hu, B.; Yang, W.Q.; Andrews, H.; Li, C.; Takeda, F. Towards a Semi-Mechanical Harvesting Platform System for Harvesting Blueberries with Fresh-Market Quality. Acta Hortic.. (in press).

17. Lobos, G.; Moggia, C.; Retamales, J.B.; Sanchez, C. Effect of mechanized (self-propelled or shaker) vs. hand harvest on fruit quality of blueberries (Vaccinium corymbosum L.) in postharvest. Acta Hortic. 2014, 1017, 141-145. [CrossRef]

18. McKibben, H.E.; Jones, P.F. Oscillating Blueberry Stripper. U.S. Patent No. 3,023,565, 6 March 1962.

19. National Research Council and Institute of Medicine. Musculoskeletal Disorders and the Workplace: Low Back and Upper Extremities; National Academy Press: Washington, DC, USA, 2001; p. 492.

20. Gomez, M.I.; Hwang, S.; Stark, A.D.; May, J.J.; Hallman, E.M.; Pantea, C.I. An analysis of self-reported joint pain among New York farmers. J. Agric. Saf. Health 2003, 9, 143-157. [CrossRef] [PubMed]

21. Olmstead, J.W.; Armenta, H.P.R.; Lyrene, P.M. Using sparkleberry as a genetic source for machine harvest traits for southern highbush blueberry. HortTechnology 2013, 23, 419-424.

22. Yang, W.Q.; Oregon State University, Aurora, OR, USA. Personal communication, 2014.

23. Williamson, J. University of Florida, Gainesville, FL, USA. Personal communication, 2014.

24. Mainland, C.M. North Carolina State University, Castle Hayne, NC, USA. Personal communication, 2014.

25. Strik, B.; Buller, G. Improving yield and machine harvest efficiency of 'Bluecrop' through high density planting and trellising. Acta Hortic. 2002, 574, 227-231. [CrossRef]

26. Earle-Richardson, G.; Jenkins, P.L.; Freivalds, A.; Burdick, P.; Park, S.; Lee, C.; Mason, C.; May, J.J. Laboratory evaluation of belt usage with apple buckets. Am. J. Ind. Med. 2006, 49, 21-33. [CrossRef] [PubMed]

27. Freivalds, A.; Park, S.; Lee, C.; Earle-Richardson, G.; Mason, C.; May, J.J. Effect of belt/bucket interface in apple harvesting. Int. J. Ind. Ergon. 2006, 36, 1005-1010. [CrossRef]

28. Earle-Richardson, G.; Jenkins, P.L.; Strogatz, D.; Bell, E.M.; Freivalds, A.; Sorensen, J.A.; May, J.J. Electromyographic assessment of apple bucket intervention designed to reduce back strain. Ergonomics 2008, 51, 902-919. [CrossRef] [PubMed]

29. Borg, G.A.V. Psychophysical bases of perceived exertion. Med. Sci. Sports Exerc. 1982, 14, 377-381. [CrossRef] [PubMed]

30. Freivalds, A. Biomechanics of the Upper Limbs, Mechanics, Modeling and Musculoskeletal Injuries, 2nd ed.; CRC Press: Boca Raton, FL, USA, 2011; p. 564.

31. Freivalds, A. Niebel's Methods, Standards and Work Design, 13th ed.; McGraw-Hill: New York, NY, USA, 2014; p. 747.

(C) 2017 by the authors. Licensee MDPI, Basel, Switzerland. This article is an open access article distributed under the terms and conditions of the Creative Commons Attribution (CC BY) license (http:/ / creativecommons.org/licenses/by/4.0/). 